\title{
Double object constructions in L3 English: An exploratory study of morphological and semantic constraints
}

\author{
AINARA IMAZ AgIRRE \& MARÍA DEL PILAR GARCÍA MAYO* \\ Universidad del País Vasco (UPV/EHU)
}

Received: 18/07/2013. Accepted: 11/03/2014.

\begin{abstract}
The present study examines the acquisition of double object constructions (DOCs) (Susan gave Peter an apple) by 90 Basque/Spanish learners of English as a third language (L3). The aim of this study was to explore whether (i) learners established a distinction when accepting DOCs vs. prepositional phrase constructions (PPCs) (Susan gave an apple to Peter), (ii) they were sensitive to the morphological and semantic constraints found in English DOCs and (iii) proficiency effects could be observed. Results from a self-paced reading task and an auto-paced reading task showed that Basque/Spanish learners were more accurate in morphosyntactic properties than in semantic ones. Even though learners showed difficulties in both morphological and semantic constraints, these seem to be overcome by increasing proficiency.
\end{abstract}

KEYWORDS: double object constructions, dative alternation, English, morphological constraint, semantic constraint.

\section{RESUMEN}

Este estudio analiza la adquisición de estructuras de doble objeto (double object construction) (DOCs) (Susan gave Peter an apple) por parte de 90 bilingües de euskara/castellano con inglés como tercera lengua (L3). El objetivo de este estudio es examinar (i) si los aprendices establecen diferencias a la hora de aceptar DOCs vs. estructuras preposicionales (PPCs) (Susan gave an apple to Peter), (ii) si muestran sensibilidad a las restricciones morfológicas y semánticas de los DOCs en inglés y (iii) si se observan efectos en base al nivel de conocimiento de inglés de los participantes. Los resultados obtenidos de una tarea de lectura auto-dirigida y una tarea de lectura automática indican que los bilingües euskara/castellano muestran mayor precisión en propiedades morfosintácticas que en propiedades semánticas. A pesar de las dificultades encontradas con respecto a las restricciones morfológicas y semánticas, el mayor nivel de conocimiento de la lengua parece facilitar la superación de las mismas.

PALABRAS ClAVE: estructuras de doble objeto, alternancia de dativo, inglés, restricciones morfológicas, restricciones semánticas.

*Address for correspondence: María del Pilar García Mayo. Departamento de Filología Inglesa y Alemana y de Traducción e Interpretación, Universidad del País Vasco (UPV/EHU), Spain. E-mail: mariapilar.garciamayo@ehu.es 


\section{INTRODUCTION}

The aim of the present study is to investigate the acquisition of English double object constructions (henceforth DOCs) by Basque/Spanish bilinguals. Dative alternation has been widely recognized as an example of poverty-of-stimulus construction (Perpiñán \& Montrul, 2006), that is, a construction that is difficult to acquire on the basis of the limited amount of data available to the learner. Mazurkewich and White (1984) already identified English DOCs as problematic structures even for learners of English as a first language (L1). As illustrated in (1), English allows for an unmarked Prepositional Phrase construction (PPC) and a marked DOC:

(1) a. Peter bought a house for Mary. Prepositional Phrase construction (PPC)

b. Peter bought Mary a house.

Double object construction (DOC)

The topic of dative alternation has been investigated in Spanish (Cuervo, 2007; Perpiñán \& Montrul, 2006) and English (Oh, 2010; Oh \& Zubizarreta, 2006a, b; Whong-Barr \& Schwartz, 2002) as second languages. As will be seen below, the three languages in the present study, Basque, Spanish and English, offer an interesting combination since Basque, one of the learners L1s, does not show dative alternation whereas Spanish has been claimed to exhibit alternation only in clitic-doubling structures (Demonte, 1995).

The rest of the article is structured as follows: the next section presents dative constructions in the three languages involved in the present study; section 3 summarizes the most relevant findings in the literature with regard to the acquisition of DOCs in English. In section 4 , the study itself is described followed by the reporting of the main findings (section 5) and the discussion and conclusion (section 6).

\section{DATIVE ALTERNATION IN ENGLISH, SPANISH AND BASQUE}

In this section, the typological differences between the three languages involved in this study, Basque, Spanish and English, will be briefly outlined. In English, dative alternation expresses a relationship between a goal and a theme or a recipient in two alternate ways (Cuervo, 2007): a PPC, with an indirect object headed by the preposition to in goal contexts (2a) or by the preposition for in benefactive counterparts ( $2 b$ ) and a DOC with two determiner phrases (DPs), with the dative recipient appearing before the theme, as illustrated in (3a) and (3b):
(2) a. Jane gave a present to Tom.
Goal PPC
b. George fixed a sandwich for Kate.
Benefactive PPC 

(3) a. Jane gave Tom a present.
Goal DOC
b. George fixed Kate a sandwich.
Benefactive DOC

In DOCs, the dative recipient appears before the theme. It takes some of the direct-object properties of the theme in the PPC, whereas in the DOC the recipient, receives Case from the verb and moves to the subject position in a passive sentence (Tom was given a present/Kate was fixed a sandwich). Syntactically, the theme is structurally higher than the goal in the PPC. However, in DOCs, the recipient or goal is higher than the theme (Larson, 1988; Pesetsky, 1995), as illustrated in Figure 1 (from Haegeman \& Gueron, 1999:125):

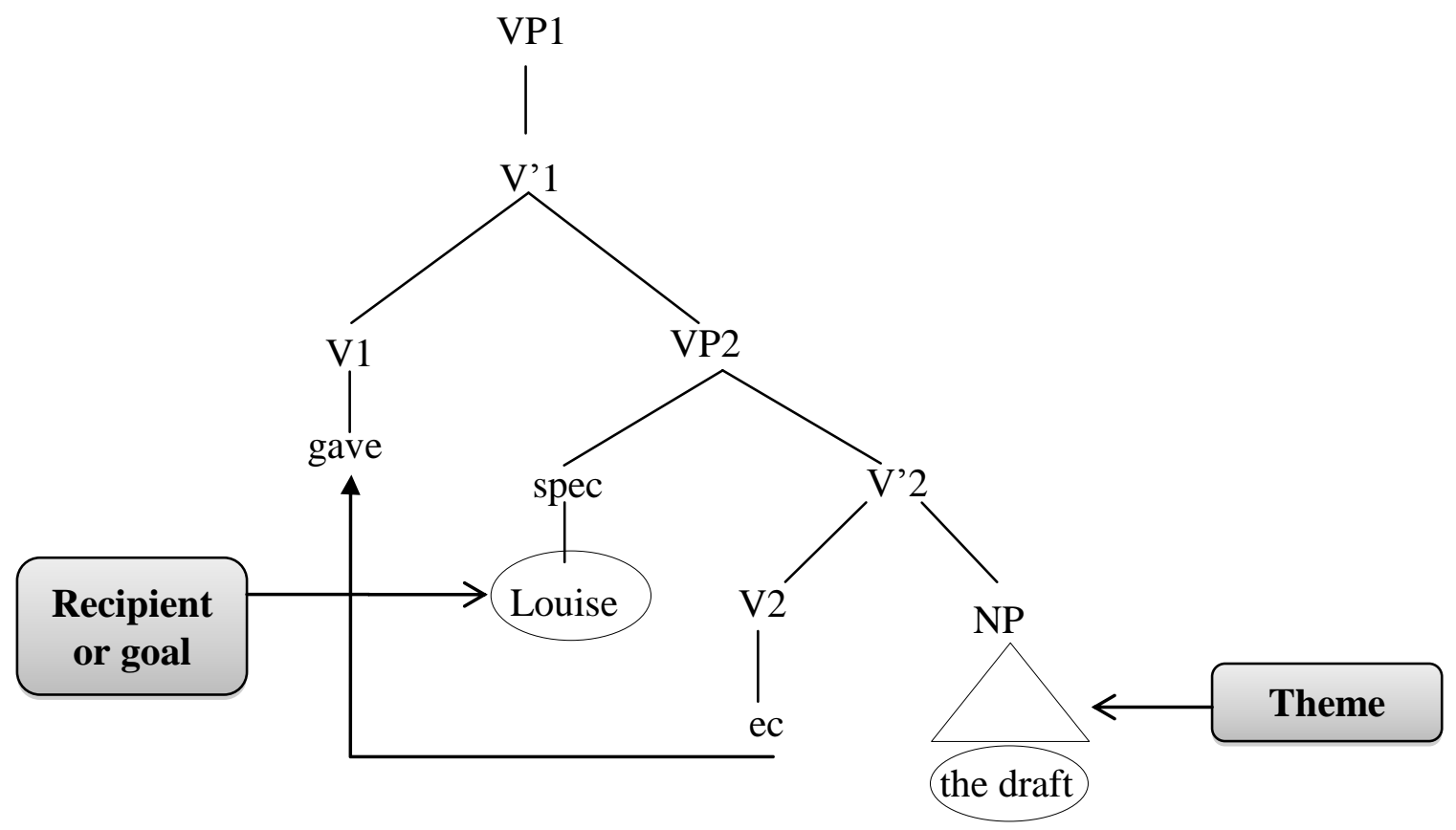

Figure 1. Syntactic structure of double object constructions

Hence, DOCs display a c-command asymmetry: the first object asymmetrically ccommands the second object, as illustrated in (4) (Larson, 1988; Marantz, 1993; Pesetsky, 1995).
a. I showed Mary herself.
b. *I showed herself Mary.

Despite the syntactic and semantic similarities between goal and benefactive DOCs, there are some reasons to differentiate the two types of verbs. Syntactically, it has been argued that only goal DOCs can be passivized (Kay, 2001), as shown in (5).

(5) a. He was given a present on his birthday.

b. *He was baked a cake on his birthday. 
Moreover, these constructions have two distinct PPC counterparts with distinct semantics. These contrasts could motivate a distinction between goal and benefactive contexts (Oh, 2010).

English DOCs feature two constraints: a semantic or possessor constraint and a morphological or Latinate constraint. DOCs encode a possession relationship between the two DPs since the referent of the first object has a possession relationship with the second object. The semantic or possessor constraint applies to both goal and benefactive verbs, as illustrated in (6) and (7).

(6) a. Lucy sent a package to New York / * Lucy sent New York a package.

b. Lucy sent a package to Mary. / Lucy sent Mary a package

(7) a. John poured some water for the balloon. / *John poured the balloon some water.

b. John poured some water for Mary. / John poured Mary some water.

Besides the semantic constraint, English DOCs also exhibit the so-called Latinate constraint: only verbs with a Germanic origin appear in a DOC and verbs of a Latinate origin are not allowed, as illustrated in (8).

(8) a. Mark gave/donated his violin to the conservatory.

b. Mark gave/*donated the conservatory his violin.

Syntactically, Spanish has a dative construction with two different alternations: V DP THEME $P_{\text {GOAL }}$ and V PP ${ }_{\text {GOAL }}$ DP ${ }_{\text {THEME, }}$ as shown in (9) ${ }^{1}$.

a. Luis mandó $\quad$ una fotografía a la niña/a Paris. V DP PP Luis send.PAST DET picture to DET girl to Paris

'Luis sent a picture to the girl/ to Paris.'

b. Luis mandó a la niña/*a Paris una fotografía. V PP DP Luis sent to DET girl to Paris DET picture

'Luis sent the girl/ *Paris a picture.'

Spanish does not allow DOCs similar to English DOCs (V DP GOAL DP THEME), as illustrated in (10):

\footnotetext{
* Luis mandó la niña una fotografía. Luis sent DET girl DET picture

'Luis sent the girl a picture.'
}

V DP DP

However, Demonte (1995) proposed that Spanish dative constructions with dative clitic doubling are equivalent to English DOCs. Consider the following example: 
(11) Luis le mandó una fotografía a la niña/*a Paris.

Luis CL sent DET picture to DET girl/ to Paris

'Luis sent a picture to the girl/ to Paris.'

When the goal is not doubled by a clitic, the $a$-phrase is a PPC, as in (9a). In contrast, when the $a$-phrase is doubled by a clitic, Demonte (1995) claims that the structure corresponds to a DOC, although its surface form is the same as a PPC. Benefactive datives lend support to this hypothesis because the preposition para appears in the DOC, but not in the PPC (Cuervo, 2007), as (12) illustrates:

a. Sara hizo la cena parasu madre. Sara cook DET dinner FOR her mother 'Sara cooked the dinner for her mother.'

b. Sara le hizo la cena a su madre. Sara CL cook DET dinner TO her mother 'Sara cooked her mother the dinner.'

Semantically, Spanish DOCs may denote two meanings: a source or a possessor. A dative argument with a transitive verb that expresses a transfer of possession is interpreted as a possessive source, as shown in (13):

(13) El ladrón le robó el bolso a la mujer.

DET thief CL steal.PAST DET purse To DET woman

'The thief stole the purse to the woman.'

A priori, Basque does not feature DOCs since the language uses only one morphological form to mark datives: the bound morpheme $-(r) i$. Datives in Basque could appear in two or three argument sentences. In two argument structures, each auxiliary allows two configurations (as shown in 14-16): without a dative morpheme (sentences in 'a' below) and with a dative morpheme (sentences in ' $b$ ' below). Whereas in three argument structures the dative morpheme is always present, as illustrated in 17 :
a. Miren-gana liburu- $a-\phi \quad$ bidal- $i$
Miren.INE book.DET.ABS send.PF
$d-u-t$.
AUX.PRS-3SG.ABS-3SG.ERG
'I send a book to Mary.'
b. Miren- $i \quad$ liburu- $a$ - $\phi \quad$ bidal- $i$
Miren.DAT book.DET.ABS send.PF
$d$-i-o-t.
AUX.PRS-3SG.ABS-3SG.DAT-1SG.ERG
'I send a book to Mary.' 
a. Miren-entzat opari-a- $\phi \quad$ presta-tu

Miren.BEN present.DET.ABS prepare.PTCP

$d-u-t$.

AUX.PRS-3SG.ABS-3SG.ERG

'I have prepared a present for Mary.'

b. Miren- $i \quad$ opari-a- $\phi \quad$ presta-tu

Miren.DAT present.DET-ABS prepare.PTCP

$d$-i-o-t.

AUX.PRS-3SG.ABS-3SG.DAT.1SG.ERG

'I have prepared a present for Mary.'

a. Miren-en jertse- $a$ - $\phi \quad$ hartu- $\phi$

Miren.GEN sweater.DET-ABS take.PF

$d-u-t$.

AUX.PRS-3SG.ABS-3SG.ERG

'I have taken Mary's sweater.'

b. Miren- $i \quad$ jertse- $a-\phi \quad$ hartu- $\phi$

Mary.DAT sweater-DET.ABS take-PF

$d$-i-o-t.

AUX.PRS-3SG.ABS-3SG.DAT-1SG.ERG

'I have taken a sweater for Mary.'
a. Aitor-ren etxe-a- $\varnothing \quad n i-k \quad$ garbitu-ko
Aitor.GEN house.DET.ABS 1 SG.ERG clean.FUT
$d-i-z u-t$.
AUX.PRS-3SG.ABS-2SG.DAT-1SG.ERG
'I will clean Aitor's house for you.'

From a syntactic point of view it has been questioned whether datives in Basque are postpositional structures or determiner phrases (DPs) (Fernández \& Ortiz de Urbina, 2010). In general, the latter position has been advocated for Basque datives (Artiagoitia, 2000; Elordieta, 2001; Fernández, 1997), that is, the dative morpheme is a declension form. But some linguists (Arregi, 2003; Arregi \& Ormazabal, 2003) argue for a derivational relationship between the two structures. Following Baker's (1988) Uniformity of Theta Assignment Hypothesis (UTAH), they claim that since both structures show the same theta-role relationship, they should both share the same level in the lay-out of the syntactic configuration and display a derivational relationship. Choosing one position or the other is beyond the scope of this paper.

Regarding semantics, unlike English, Basque does not exhibit any to or for PPC with datives (Fernández \& Ortiz de Urbina, 2010), although Arregi (2003) and Arregi and Ormazabal (2003) have proposed that datives may alternate with other postpositional structures.

In sum, the linguistic characterization of dative constructions in the three languages involved in this study varies considerably. English features both a PPC and a DOC to express dative alternation, although there are semantic and morphological constraints in the latter. 
Spanish also features a PPC and it has been argued that there is a dative alternation construction only found in clitic doubling structures. As for Basque, some authors (Fernández \& Ortiz de Urbina, 2010) claim that dative alternation is not found in this language.

In the following section studies that have considered the issue of dative alternation in English as an L1 and as an L2 will be summarized. Three research questions will be entertained and corresponding hypotheses presented on the basis of previous research findings.

\section{THE ACQUISITION OF DOCs}

As mentioned above, argument alternations represent an interesting poverty of stimulus argument (or learnability problem) in language acquisition (Pinker, 1989). Several studies have considered the difficulty of acquiring semantic and morphological restrictions that constrain dative alternation without access to negative evidence. In this section we will focus on those studies that have considered English both as an L1 or an L2.

Mazurkewich and White (1984) proposed that ditransitive verbs show two subcategorization frames ruled by lexical redundancy: [NP PP] (i.e. John gave a book to Mary) and [NP NP] (i.e. John gave Mary a book). They suggested that children learning English as their L1 are not conscious of the semantic and morphological constraints of the lexical redundancy rule, and consequently, children overgeneralize the alternation to verbs that disallow it, as (18) illustrates:

(18) *Nancy drove Ted the car.

(Mazurkewich \& White, 1984: 269)

Early studies on the L2 acquisition of DOCs focused on the markedness of the construction (DOCs were less frequent in the input than PPCs and, therefore, were considered the marked form in the pair) whereas more recent studies have shifted their focus to transfer issues. Mazurkewich $(1984,1985)$ elicited dative constructions from L1 French and L1 Inuit learners of L2 English. The findings of her study indicated that learners acquired PPCs before DOCs, as hypothesized by markedness. In a similar vein, Hawkins (1987) analyzed the production of L1 French learners of English who completed a grammaticality judgment task (GJT) and a sentence reconstruction task. His findings also revealed that L1 French learners acquired PPCs before DOCs. Besides, he also reported that in DOCs learners were more accurate with goal than with benefactive verbs. On the basis of these findings, Hawkins suggested the following developmental sequence for the acquisition of DOCs in English:

Stage 1: the acquisition of PPCs precedes the acquisition of DOCs.

Stage 2: In PPCs, the acquisition of to-verbs precedes the acquisition of for-verbs. 
Stage 3: In DOCs, the acquisition of to-verbs precedes the acquisition of for-verbs.

Stage 4: The acquisition of specific language constraints.

In more recent studies, Whong-Barr and Schwartz (2002) investigated the acquisition of English to and for-dative alternation by L1 English, L1 Japanese and L1 Korean children. DOCs are not allowed in Japanese, Korean has a form equivalent to the English for-dative form but to-datives are not allowed. Whong-Barr and Schwartz used an oral GJT with puppets for children. Findings provided evidence in favor of overgeneralization, like in L1 acquisition, since both Japanese and Korean participants allowed illicit to-DOCs. Besides, unlike the Korean learners, the Japanese learners accepted illicit for-DOC, supporting an L1transfer explanation. Whong-Barr and Schwartz interpreted the results as clear support for the Full Transfer/Full Access (FT/FA) model (Schwartz \& Sprouse, 1994, 1996) since learners were able to acquire L2 English properties that were similar to those of their L1.

Oh and Zubizarreta (2003, 2006a, 2006b) replicated Whong-Barr and Schwartz's methodology using a GJT with 65 adult Korean learners of L2 English with different proficiency levels; 73 L1 Mandarin speakers were added in a second experiment. Strong asymmetries were found between learners' judgments of goal and benefactive DOCs. In fact, both L1 groups displayed a similar preference pattern for goal DOCs over benefactive DOCs. However, Oh \& Zubizarreta (2006b) found that although advanced learners showed some asymmetries, they decreased as the learners' proficiency level in the target language increased.

Oh (2010) investigated the acquisition of dative alternation by 33 L1 Korean learners of English. Findings from an acceptability judgment task indicated that increasing proficiency allowed learners to overcome negative transfer effects. In fact, most advanced learners were able to acquire the semantic properties of English DOCs. Oh claimed that these findings showed evidence for the syntax-semantics interface since developing sensitivity to the semantics of English DOCs was necessary for the acquisition of the syntax of the construction.

Kang (2011) analyzed a corpus of written data produced by eight L1 Korean children (aged 10-13). Korean is an agglutinative language where a (dative) case is assigned by adding the postpositional -cwe morpheme. The findings of the study also revealed that Korean learners acquired PPCs before DOCs.

In sum, previous findings have shown L1 transfer effects in the acquisition of English dative alternation by learners from different backgrounds. Based on Markedness, it was suggested that the acquisition of PPCs precedes the acquisition of DOCs. Moreover, assuming full transfer from the L1, Whong-Barr and Schwartz (2002) and Oh (2010) found that similarities between the native and the target language would facilitate the acquisition of a specific construction, whereas differences between the two languages would hinder the 
acquisition due to a negative blocking effect of the L1. Nevertheless, these difficulties seemed to be overcome by increasing proficiency.

As mentioned above, datives are expressed differently in the three languages involved in the present study. On the basis of the literature review made in the previous section, the following research questions are entertained:

RQ 1: Are Basque/Spanish bilinguals sensitive to double object constructions (DOC) in L3 English? Do Basque/Spanish bilinguals show differences in goal and benefactive verbs?

Following Mazurkewich (1984, 1985), Hawkins (1987) and Oh (2010) we hypothesize that learners would be more accurate in PPCs due to the fact that they may transfer the structure from one of their L1s. However, as proficiency increases, learners are expected to acquire the semantic restrictions and overcome the negative blocking effects in DOCs.

Regarding goal and benefactive verbs, following Hawkins (1987), Mazurkewich (1984, 1985) and Oh (2010) Basque/Spanish learners are expected to show asymmetries in evaluating both verb types. Learners are expected to be more accurate in goal verbs since it has been claimed to be the unmarked form as opposed to the marked benefactive verbs.

RQ 2: Are Basque/Spanish bilinguals sensitive to semantic and morphological constraints?

Taking into consideration the cross-linguistic differences between the three languages involved in the present study, contrasting hypotheses are made for both semantic and morphological constraints. On the one hand, assuming Full Transfer effects (Oh, 2010; Schwartz \& Sprouse, 1994, 1996; Whong-Barr \& Schwartz, 2002) and given the similarities between the three languages regarding the possessor constraint, Basque/Spanish bilinguals are expected to show native-like accuracy in discarding illicit DOCs.

On the other hand, Basque/Spanish are expected to display negative blocking effects (Oh, 2010) due to the fact that none of the languages features the Latinate constraint. Thus, participants are expected to accept illicit Latinate DOCs. Besides, following Mazurkewich and White (1984), these learners could overgeneralize and accept illicit DOCs.

RQ 3: Does proficiency level play a role regarding learners' sensitivity to DOCs?

Proficiency differences are expected to play a role. Thus, advanced learners are expected to be more native-like in all conditions than elementary and intermediate learners (Oh, 2010; Perpiñán \& Montrul, 2006) in PPCs and in DOCs, except for the semantic 
constraint. In this condition, assuming full transfer effects, participants are expected to be native-like.

\section{THE PRESENT STUDY}

\subsection{Participants}

Ninety $(\mathrm{n}=90)$ Basque/Spanish bilinguals and 12 native speakers of American English participated in the study. All participants were highly proficient speakers in both Basque and Spanish since all of them had acquired Basque before the age of 3. All participants had received their formal instruction in Basque at school and were doing their university studies in Basque. Besides, all of them had the EGA (Euskara Gaitasun Agiria), a certificate equivalent to the $\mathrm{C} 1$ in the Common European Framework. Participants were undergraduate students at a major Spanish university. They completed an Oxford Placement Test (OPT) (Syndicate, 2001) in order to determine their proficiency level in English. On the basis of the results, the participants were classified as elementary, intermediate and advanced.

\subsection{Materials and procedure}

In order to examine the L3 learners' sensitivity to English DOCs, the participants performed two online acceptability judgment tasks: a self-paced reading task (SPRT) and an auto-paced reading task (APRT). In both tasks, participants were asked to evaluate the acceptability of sentences in English in a 7 point Likert scale (1 being completely acceptable and 7 completely unacceptable). When piloting the experiment, these participants preferred having 1 as completely acceptable and 7 as completely unacceptable in the Likert scale. Hence, on the basis of the participants' preferences in the pilot study, this layout for the Likert scale was chosen. In order to be included in the data analysis, participants needed to reach a $60 \%$ accuracy rate in the filler sentences.

Test materials consisted of 12 conditions that belonged to three main components: the PPC, the goal or benefactive verb and the language specific constraint. The PPC condition was used to test the sensitivity to the prepositional construction (which does not differ from the one in one of their L1s, Spanish) in comparison to the DOC variant. The second component was used to test learners' acceptability of the two different types of dative constructions in English and the third component tested the specific constraints for dative alternation found in English: the morphological constraint and the semantic constraint. In order to analyze possible permissibility of these specific constraints, Latinate verbs were used to test the morphological constraint and conditions with exceptional verbs tested the semantic constraint as neither verb type allows DOCs. Besides, there was a third control condition in 
which DOCs are allowed in English. Test materials consisted of 72 experimental items, which had a PPC and a DOC counterpart. Table 1 features a detailed distribution of test items.

\begin{tabular}{|c|cc|c|c|}
\cline { 2 - 5 } \multicolumn{1}{c|}{} & \multicolumn{2}{c|}{ PPC } & \multicolumn{2}{c|}{ DOC } \\
\cline { 2 - 5 } & Goal & Benefactive & Goal & Benefactive \\
\hline \multirow{4}{*}{ Latinate verbs } & Suggest & Construct & Suggest & Construct \\
& Return & Collect & Return & Collect \\
& Explain & Obtain & Explain & Obtain \\
& Repeat & Create & Repeat & Create \\
& Describe & Select & Describe & Select \\
& Recite & Design & Recite & Design \\
\hline \multirow{4}{*}{ Exceptional } & Push & Solve & Push & Solve \\
verbs & Pull & Keep & Pull & Keep \\
& Drag & Fix & Drag & Fix \\
& Whisper & Open & Whisper & Open \\
& Shout & Finish & Shout & Finish \\
& Yell & Wash & Yell & Wash \\
\hline \multirow{4}{*}{ Control verbs } & Kick & Build & Kick & Build \\
& Throw & Draw & Throw & Draw \\
& Tell & Get & Tell & Get \\
& Show & Fix & Show & Fix \\
& Bring & Buy & Bring & Buy \\
& Hand & Find & Hand & Find \\
\hline
\end{tabular}

Table 1. Distribution of test materials

All items were divided into two lists of 36 experimental items each so that participants did not evaluate the same experimental item twice in the same task. The same materials were used in both the SPRT and the APRT. However, lists and tasks were randomized in order to avoid possible task effects. Besides experimental items, participants also evaluated 36 control items (24 acceptable and 12 unacceptable items). Half of the items had 6 and the other half had 7 tokens.

\section{RESULTS}

This section presents the accuracy and reaction time (RT) data from both the SPRT and the APRT. Participants' accuracy data were submitted to one-way ANOVA analysis in order to answer the three research questions. Regarding accuracy, no significant differences were found between the timed and the untimed tasks, as illustrated in Figure 2. Thus, accuracy findings from both tasks will be reported together. In order to interpret learners' evaluations in the following figures, recall that when the mean evaluation was closer to 1 the judgments were more accurate, whereas the mean evaluation close to 7 showed inaccurate judgments. 


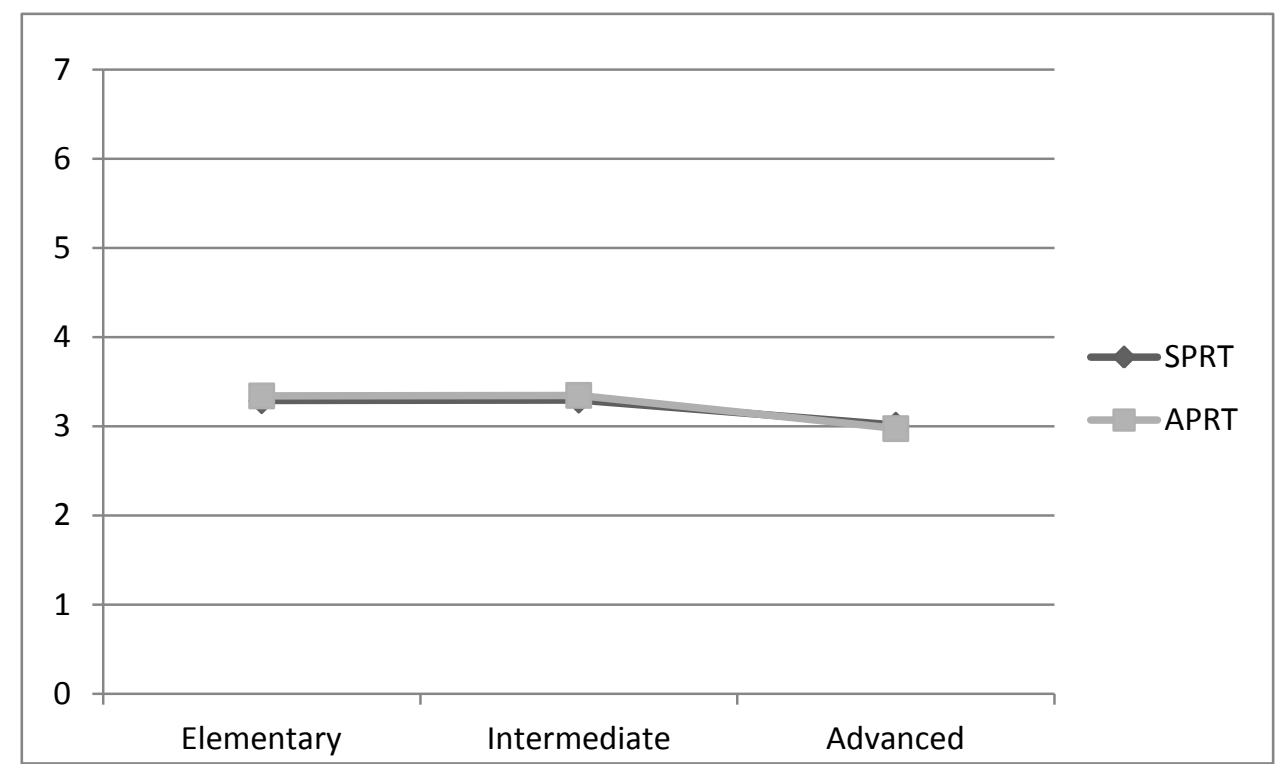

Figure 2. Task differences in the three proficiency groups

The first research question aimed at examining the sensitivity to DOCs. In order to analyze these effects DOCs were compared to PPCs. The analyses revealed statistically significant differences in the elementary $(F(1,2158)=466.081 ; p<.0001)$, intermediate $(F$ $(1,2158)=44.778 ; p<.0001)$ and advanced $(F(1,2158)=428.365 ; p<.0001)$ groups. Learners in all proficiency groups showed higher accuracy in PPCs than in DOCs, as displayed in Figure 3.

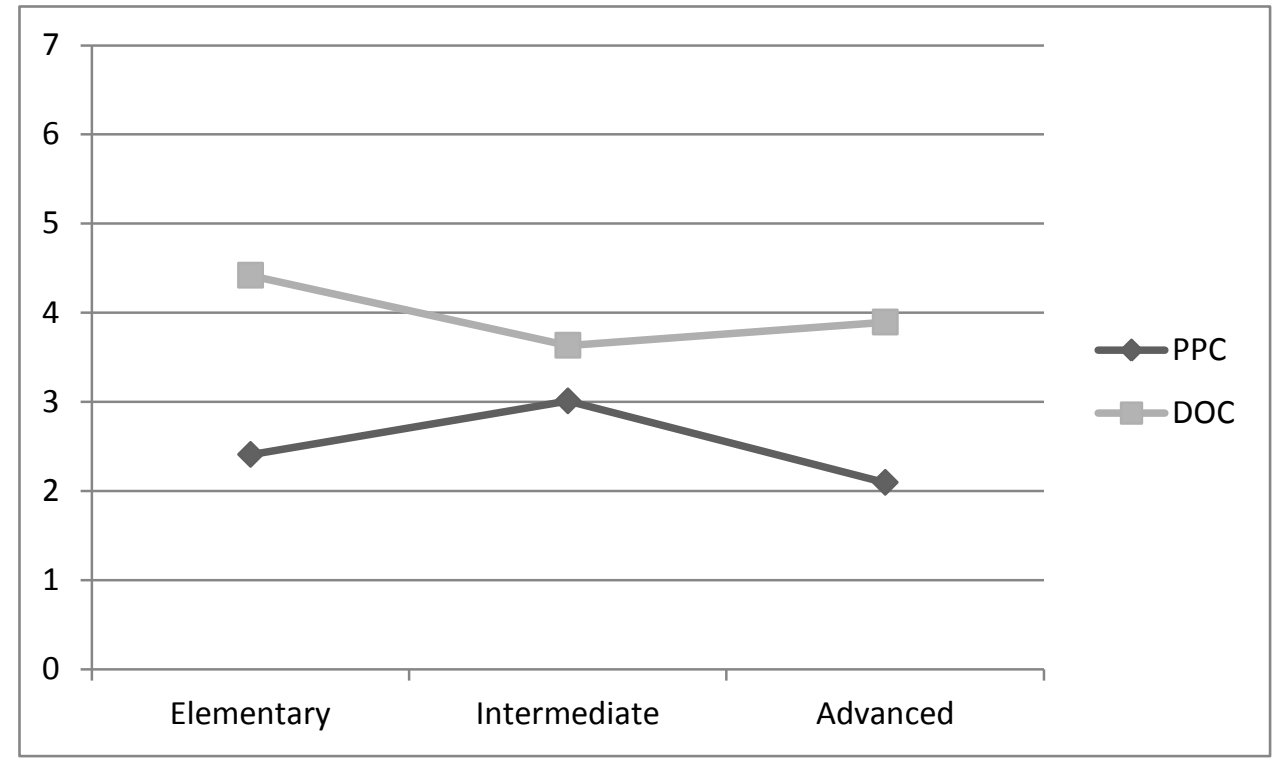

Figure 3. Differences between PPC and DOC in the three proficiency groups

Nevertheless, accuracy in goal and benefactive DOCs was checked to analyze whether differences occur in the judgments of these constructions. In PPCs, one-way ANOVA 
analyses revealed statistically significant differences $(F(1,1079)=7.263 ; p=.007)$ between goal and benefactive verbs only in the intermediate group. In fact, intermediate learners were more accurate in benefactive verbs than in goal verbs, as illustrated in Figure 4.

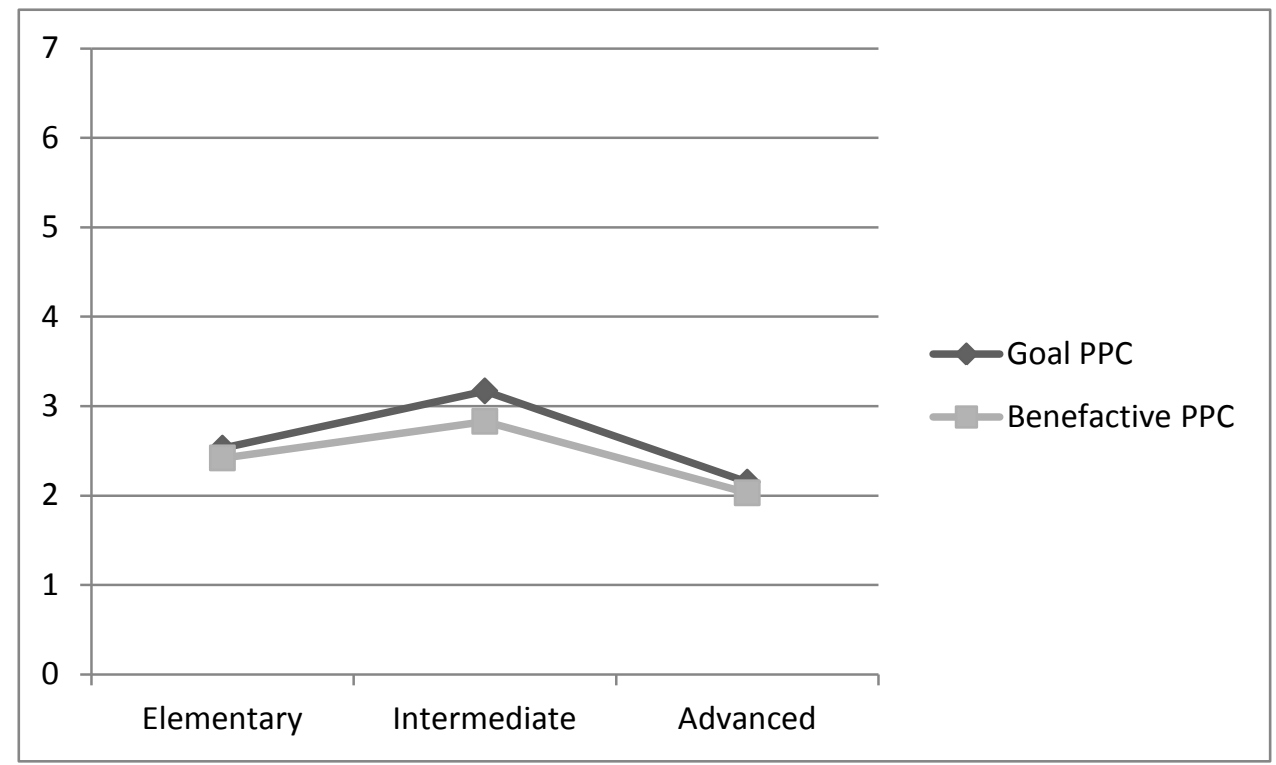

Figure 4. Mean accuracy in goal and benefactive PPCs in each proficiency group

In DOCs, one-way ANOVA analyses revealed statistically significant differences between both verb types in the elementary $(F(1,1079)=39.216 ; p<.0001)$ and the advanced $(F(1,1079)=7.517 ; p=.006)$ groups. Learners in the elementary group were more accurate in goal verbs than in benefactive verbs. In contrast, advanced learners showed higher accuracy in benefactive verbs than in goal verbs, as shown in Figure 5.

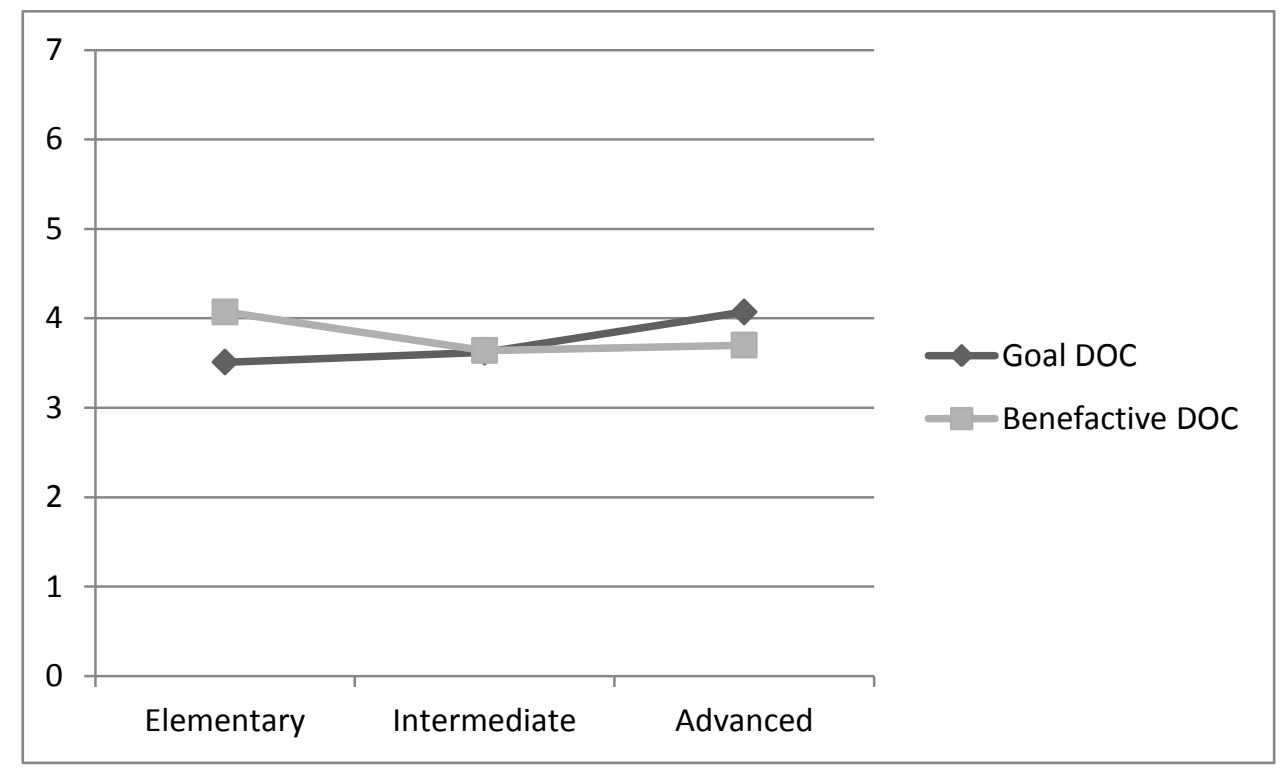

Figure 5. Mean accuracy in goal and benefactive DOCs in each proficiency group 
Regarding the second research question, that is, the learners' sensitivity to the morphological and the semantic constraints, no differences between the experimental conditions in the PPC in any of the proficiency groups were found. In goal verbs, when Latinate and exceptional as well as control DO verbs were compared in each proficiency group, statistically significant differences were found in the elementary $(F(2,1077)=$ $58.446 ; p<.0001)$, the intermediate $(F(2,1077)=18.604 ; p<.0001)$ and the advanced $(F(2$, $1077)=15.187 ; p<.0001)$ groups, as displayed in Figure 6. Post hoc Tukey tests revealed statistically significant differences between control DO verbs when compared to Latinate and exceptional verbs in the elementary (Latinate: $p=.002$; exceptional: $p<.0001$ ), intermediate (both $p$-values<.0001) and advanced (both $p$-values<.0001) groups. However, no differences were found between Latinate and exceptional verbs in any of the proficiency groups.

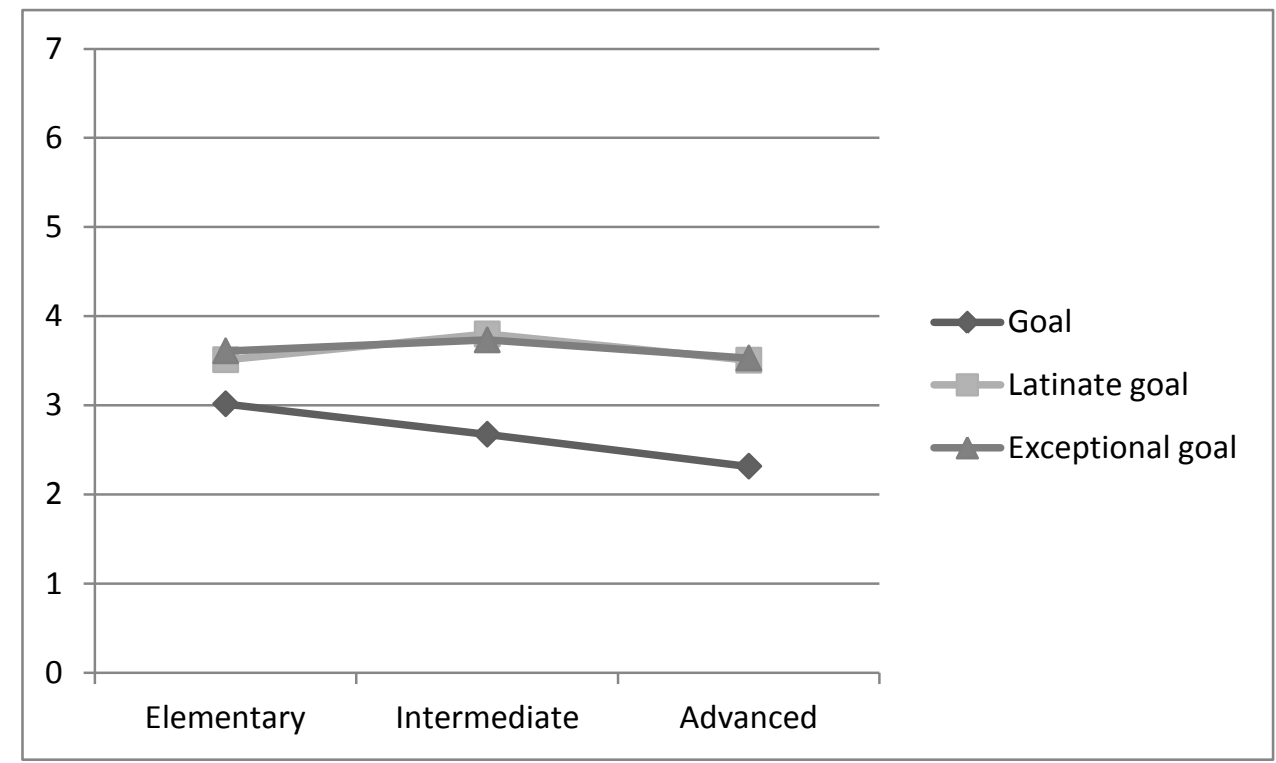

Figure 6. Differences between goal DO conditions in the three proficiency groups

Moreover, in the comparison of benefactive verbs in each group, statistical analyses revealed significant differences between the experimental DO conditions in the elementary $(F$ $(2,1077)=49.172 ; p<.0001)$ and the advanced $(F(2,1077)=49.709 ; p<.0001)$ groups. Post hoc pairwise analyses indicated statistically significant differences between control DO verbs and exceptional verbs in the elementary group $(p=.031)$. On the other hand, in the advanced group differences were found when the control DO verbs were compared to both Latinate and exceptional verbs (both $p$-values<.0001). Figure 7 displays the mean accuracy in benefactive DO conditions. 


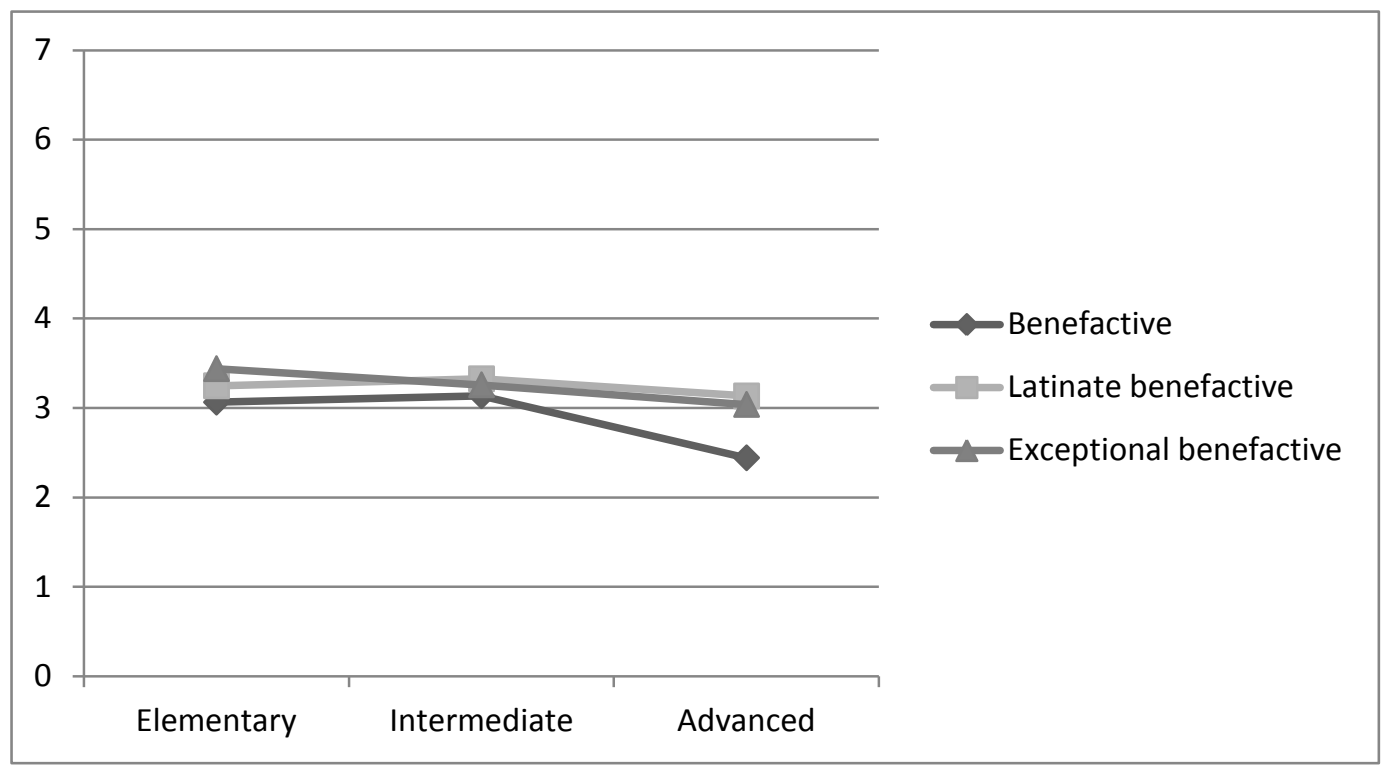

Figure 7. Differences between benefactive DO conditions in the three proficiency groups

Regarding proficiency effects, a general analyses between proficiency groups indicated statistically significant differences between groups $(F(2,6479)=16.643 ; p<.0001)$. Besides, post-hoc Tukey analyses indicated significant differences between advanced and native speakers groups when compared to both elementary and the intermediate groups ( $p$ values<.0001).

Moreover, when proficiency groups were compared in each experimental condition in goal verbs, one-way ANOVA analyses revealed that the three experimental groups evaluated PPCs similarly. However, significant differences were found when compared to native English speakers in these conditions ( $p$-values<.0001). In contrast, ANOVA analyses in the DOCs showed statistically significant differences for the comparison of all groups (except for the comparison of intermediate and advanced groups) in the control goal verbs as well as exceptional DO verbs ( $p$-values<.0001). Nevertheless, the analysis of Latinate verbs revealed statistically significant differences only between experimental groups and native speakers $(p$ values<.0001), as shown in Figure 8.

In benefactive verbs, proficiency benefits for advanced ( $p$-values $<.0001)$ were found in PPCs in control and exceptional conditions. However, the ANOVA comparison of the native group with the experimental groups also revealed statistically significant differences ( $p$ values<.0001). In contrast, in the Latinate condition intermediate learners outperformed both the elementary and the advanced groups ( $p$-values<.0001) whereas statistically significant differences were found when experimental groups were compared to natives. On the other hand, in control DO verbs significant differences were found between advanced and natives when compared to elementary and intermediate learners ( $p$-values<.0001). However, in Latinate and exceptional verbs, statistically significant differences were found for natives ( $p$ - 
values<.0001) as well as differences between elementary and intermediate groups (Latinate: $p$ $=.032$; exceptional: $p=.002$, as shown in Figure 9 .

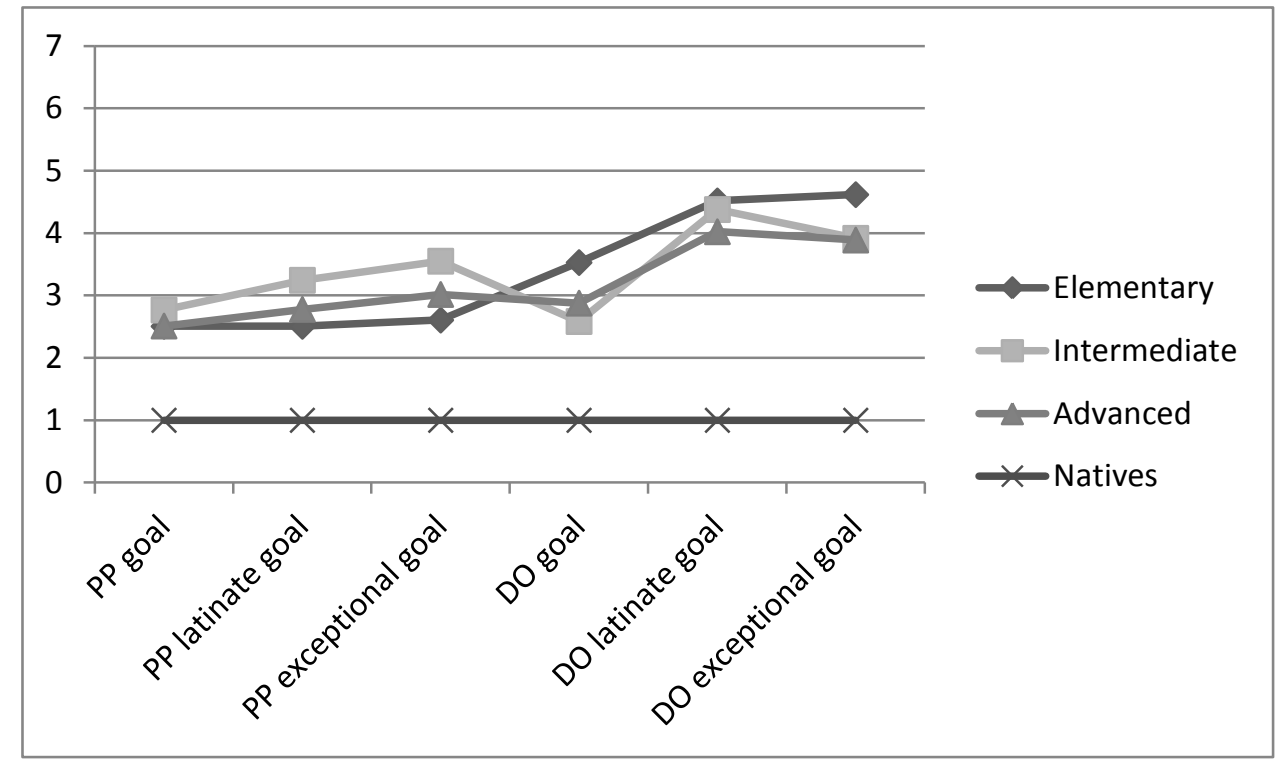

Figure 8. Between groups differences in experimental conditions in goal verbs

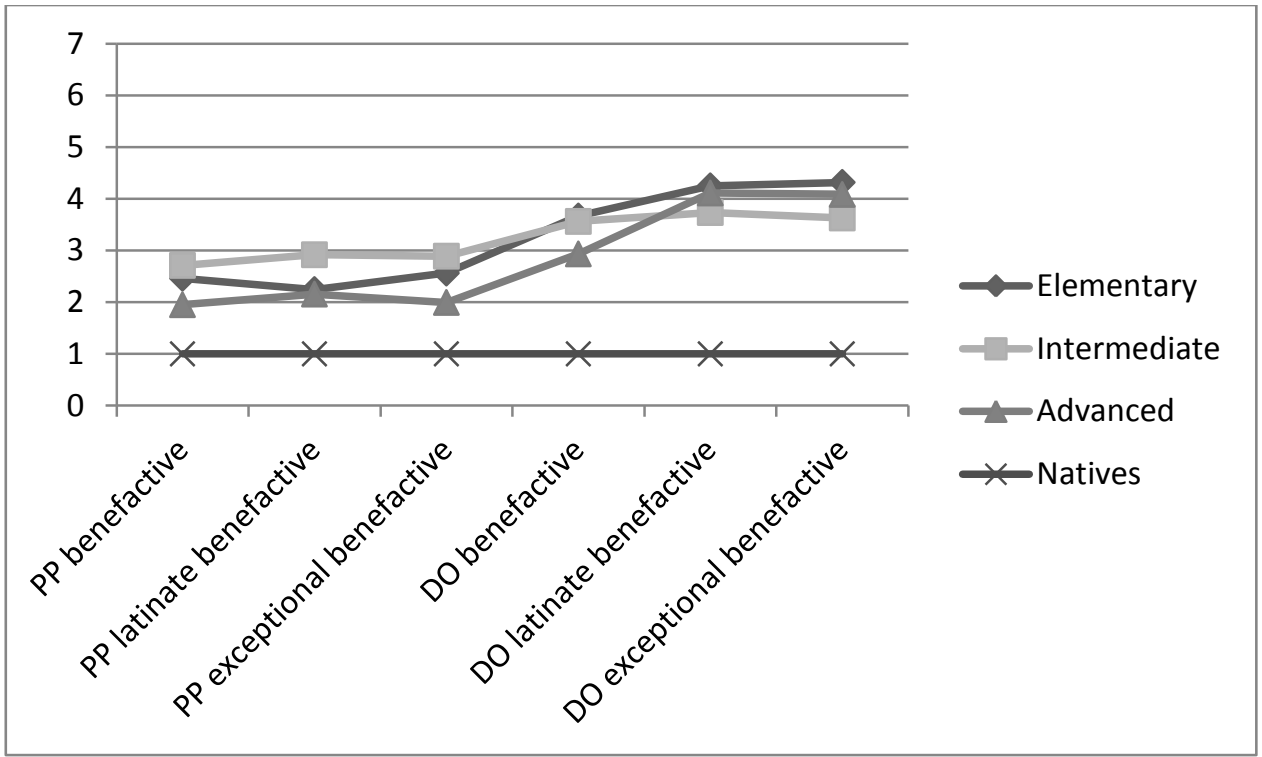

Figure 9. Between groups differences in experimental conditions in benefactive verbs

In sum, participants in all proficiency groups were more accurate in PPCs than in DOCs and response delays were longer in the latter. On the other hand, proficiency seems to be playing a role since higher proficiency learners were more accurate in evaluating the test items. Nonetheless, even participants with an advanced proficiency level were not as accurate as the native control group in judging the experimental sentences. 


\section{DISCUSSION}

This section examines the findings from two acceptability judgment tasks designed to analyze the acquisition of DOCs in L3 English by Basque/Spanish bilinguals.

The first research question explored whether Basque/Spanish learners of L3 English would be sensitive to DOCs, in other words, whether they could evaluate DOCs accurately. This is precisely what the findings showed: Basque/Spanish bilinguals were more native-like in PPCs than in DOCs in the three experimental groups, not even the more advanced learners showed native-like accuracy. In line with Mazurkewich (1984, 1985) and Hawkins (1987), findings seem to indicate that learners were more accurate in morphosyntactic properties (i.e. PPC) than in semantic properties (i.e. DOC). However, asymmetries in goal and benefactive verbs (also reported by Oh (2010)) indicate that higher accuracy in PPCs could not be explained by markedness.

The second research question examined the sensitivity of Basque/Spanish bilinguals to semantic and morphological constraints. Evidence from L2 research on DOCs indicated that learners should show native-like accuracy in constructions that are present in their L1. However, constructions not present in the L1 would lead to negative blocking effects that could be overcome by increasing proficiency. Participants were expected to show difficulties in evaluating DOCs since a comparable structure is not found in either Basque or Spanish. However, if full transfer is assumed, learners were expected to show native-like accuracy in rejecting illicit Latinate DO verb.

Interestingly, findings in the present study revealed asymmetries in evaluating goal and benefactive verbs in the most advanced group. Elementary and intermediate learners showed sensitivity both to the semantic and morphological constraints in goal verbs. Even though learners in all proficiency groups showed difficulties in accepting licit DOCs, the Latinate constraint was not evaluated accurately. In fact, similar difficulties were found in semantic and morphological constraints. For the illicit Latinate DO verbs, negative blocking effects were found in both goal and benefactive conditions. The acceptance of Latinate DOs confirms previous research by Oh (2010).

Besides, performance in goal and benefactive contexts exhibited clear asymmetries also confirming previous research (Oh, 2010; Oh \& Zubizarreta, 2006a, b). In goal conditions, learners in the three proficiency groups showed sensitivity to this specific constraint. However, in benefactive contexts, learners in the elementary and the intermediate levels behaved in a similar manner for DOCs. Only the more advanced group showed some sort of sensitivity. In these conditions, assuming L1 transfer effects at the initial stages (Oh, 2010; Whong-Barr \& Schwartz, 2002), native-like judgments were expected even for elementary learners. However, learners in the three proficiency groups showed problems disregarding illicit DOCs. Thus, full transfer effects do not seem to be supported by the evidence in the present study. Moreover, Basque/Spanish learners seem to display overgeneralization effects 
similar to Mazurkewich and White's (1984) participants in the lower proficiency group but also in benefactive verbs.

Regarding proficiency, research question 3 examined whether learners with advanced proficiency level would be more accurate in evaluating experimental items as reported by Perpiñán \& Montrul (2006) and Oh (2010). Learners in the elementary, the intermediate and the advanced group did not show native-like accuracy in any of the experimental conditions. In fact, the similarities regarding the possessor constraint in the three languages involved in the study did not seem to facilitate accuracy. In general, higher proficiency seems to be beneficial for learners' accuracy in judging experimental items. Nonetheless, increasing proficiency level does not mean higher accuracy in all conditions.

\section{CONCLUSION}

The present study has examined the acquisition of DOCs in English by Basque/Spanish bilinguals with regard to morphological and semantic constraints. Asymmetries were found between goal and benefactive verbs. However, evidence from both verb types revealed more target-like accuracy in morphosyntactic properties when compared to semantic properties. Findings did not indicate any full transfer effects from the L1 since, even in semantic constraints, learners showed difficulties in evaluating illicit exceptional DOCs. Besides, morphological constraints seem to be subject to negative blocking effects that are not overcome by increased proficiency. Thus, this study provides evidence for the difficulty in the acquisition of semantic aspects in the target language (Slabakova \& Montrul, 2002).

What this study has shown is that Basque/Spanish bilingual learners are more accurate in PPC than in DOCs, that there are asymmetries in their rating of goal and benefactive verbs, not always in the direction expected on the basis of previous research and that, in general, increasing proficiency level does not mean higher accuracy in all conditions. Much more research on this topic is needed. For example, the present study has used two online tasks, a SPRT and an APRT. Future work should also considered offline measures and triangulate the data generated by the two modes. Besides, future work should consider whether some of the predictions made by third language acquisition models (García Mayo \& Rothman, 2012) could shed some light on the data on DOCs in L3 English.

\section{ACKNOLEDGEMENTS}

The authors want to thank the participants of the study because without their time this project would not have been possible. The first author wants to thank the University of the Basque Country (UPV/EHU) for a pre-doctoral scholarship (Reference Number: PIFUPV11/ 2011). Both authors wish to acknowledge funding from the following research grants: IT-311-10 (Basque Goverment), UFI 11/06 (UPV/EHU). All errors remain our responsibility. 


\section{NOTES}

1. Here are the abbreviations we use in the Spanish and Basque glosses: $\mathrm{ABS}=$ absolutive, $\mathrm{AUX}=$ auxiliary, $\mathrm{BEN}=$ benefactive; $\mathrm{CL}=$ clitic, $\mathrm{DAT}=$ dative, $\mathrm{DET}=$ determiner, $\mathrm{ERG}=$ ergative, $\mathrm{FUT}=$ future, GEN $=$ genitive, $\mathrm{INE}=$ inessive, $\mathrm{PF}=$ perfective, $\mathrm{PRS}=$ present, $\mathrm{PST}=$ past, PTCP $=$ participle, $\mathrm{SG}=$ singular, $1=$ first person, $2=$ second person, $3=$ third person. We used the Leipzig glossing rules, see http://www.eva.mpg.de/lingua/resources/glossing-rules.php .

\section{REFERENCES}

Arregi, E. (2003). On Dative Alternations in Basque. Manuscript. University of the Basque Country (UPV/EHU).

Arregi, E. \& Ormazabal, J. (2003). Aditz ditrantsitiboen barne-egitura (The internal structure of ditransitive verbs). In J. M. Makazaga \& B. Oyharçabal (Eds.), Euskal gramatikari buruzko eta literaturari buruzko ikerketak XXI. mendearen atarian. Gramatika gaiak (Studies on Basque grammar and literature in the XXI century. Grammar topics) (pp. 119-136). Bilbo: Euskaltzaindia.

Artiagoitia, X. (2000). Hatsarreak eta parametroak lantzen (Working on principles and parameters). Gasteiz: University of the Basque/Country (UPV/EHU) and Arabako Foru Aldundia.

Baker, M. (1988). Incorporation: A Theory of Grammatical Function Changing. Chicago: University of Chicago Press.

Cuervo, M. C. (2007). Double object in Spanish as a second language. Studies in Second Language Acquisition, 28, 583-615.

Demonte, V. (1995). Dative alternation in Spanish. Probus, 7, 5-30.

Elordieta, A. (2001). Verb Movement and Constituent Permutation in Basque. Utrecht: LOT.

Fernández, B. (1997). Egiturazko kasuaren erkaketa euskaraz (The comparison of structural case in Basque). Bilbo: University of the Basque Country (UPV/EHU).

Fernández, B. \& Ortiz de Urbina, J. (2010). Datiboa hiztegian (Datives in the dictionary). Bilbao: University of the Basque Country (UPV/EHU).

García Mayo, M. P. \& Rothman, J. (2012). L3 morphosyntax in the generative tradition: From the initial state and beyond. In J. Cabrelli Amaro, S. Flynn \& J. Rothman (Eds.), Third Language Acquisition in Adulthood (pp. 9-32). Amsterdam: John Benjamins.

Haegeman, L. \& Guéron, J. (1999). English Grammar: A Generative Perspective. Oxford: Blackwell.

Hawkins, R. (1987). Markedness and the acquisition of the English dative alternation by L2 speakers. Second Language Research, 29, 20-55.

Kang, S. (2011). The acquisition of English dative constructions by Korean EFL children. Proceedings of The 16th Conference of Pan-Pacific Association of Applied Linguistics (pp. 6267). Retrieved from the Internet on 1 April, 2013.

Kay, P. (2001). Argument Structure Constructions and the Argument-Adjunct Distinction. Unpublished manuscript, University of California, Berkeley, CA.

Larson, R. K. (1988). On the double object construction. Linguistic Inquiry, 19, 335-391.

Marantz, A. (1993). Implications for asymmetries in double object construction. In S. Mchombo (Ed.), Theoretical Aspects of Bantu Grammar (pp. 113-151). Stanford, CA: CSLI Publications.

Mazurkewich, I. (1984). The acquisition of the dative alternation by second language learners and linguistic theory and linguistic theory. Language Learning, 34, 91-109.

Mazurkewich, I. (1985). Syntactic markedness and language acquisition. Studies in second language acquisition, 7, 15-36.

Mazurkewich, I. \& White, L. (1984). The acquisition of the dative alternation: Unlearning overgeneralizations. Cognition, 16, 261-283.

Oh, E. (2010). Recovery from first language transfer: The second language acquisition of double objects by Korean speakers. Second Language Research, 26, 407-439.

Oh, E. \& Zubizarreta, M. L. (2003). Does morphology affect transfer? The acquisition of English double objects by Korean native speakers. In A. Burgos, L. Micciulla \& C. Smith (Eds.), 
Proceedings of the 28th Annual Boston University Conference on Language Development (pp. 402-413). Somerville, MA: Cascadilla Press.

Oh, E. \& Zubizarreta, M. L. (2006a). Against morphological transfer. In K. U. Deen, J. Nomura, B. Schulz \& B. D. Schwartz (Eds.), Proceedings of the Inaugural Conference on Generative Approaches to Language Acquisition: North America (pp. 261-272). Honolulu, HI: University of Connecticut.

Oh, E. \& Zubizarreta, M. L. (2006b). A Case Study of Structural Transfer: The Acquisition of English Double Objects by Adult Korean Speakers. Unpublished manuscript, University of Southern California, Los Angeles, CA.

Perpiñan, S. \& Montrul, S. (2006). On binding asymmetries in dative alternation construction in L2 Spanish. In C. A. Klee \& T. L. Face (Eds.), Selected Proceedings of the 7th Conference on the Acquisition of Spanish and Portuguese as First and Second Languages (pp. 135-148). Somerville, MA: Cascadilla Proceedings Project.

Pesetsky, D. (1995). Zero Syntax: Experiencers and Cascades. Cambridge, MA: MIT Press.

Pinker, S. 1989. Learnability and Cognition: The Acquisition of Argument Structure. Cambridge, MA: MIT Press.

Schwartz, B. D. \& Sprouse, R. A. (1994). Word order and nominative case in nonnative language acquisition: A longitudinal study of (L1 Turkish) German interlanguage. In: T. Hoekstra and B. D. Schwartz (Eds.), Language Acquisition Studies in Generative Grammar (pp. 317-368). Amsterdam: John Benjamins.

Schwartz, B. D. \& Sprouse, R. A. (1996). L2 cognitive states and the full transfer/full access model. Second Language Research, 12, 40-72.

Slabakova, R. \& Montrul, S. (2002). On viewpoint aspect and its L2 acquisition: A UG perspective. In R. Salaberry \& Y. Shirai (Eds.) Tense-aspect morphology in L2 acquisition (pp. 363-395). Amsterdam: John Benjamins

Syndicate, U.C.L.E. (2001) Quick Placement Test. Oxford: Oxford University Press.

Whong-Barr, M. and Schwartz, B. D. (2002). Morphological and syntactic transfer in child L2 acquisition of the English dative alternation. Studies in Second Language Acquisition, 24, 579616. 